\title{
An Empirical Study of the Impact of Internet Financial Reporting on Stock Prices
}

Syou-Ching Lai. National Cheng Kung University, Taiwan. sclai@mail.ncku.edu.tw

Cecilia Lin. University of Portland, USA. lin@up.edu

Hung-Chih Li. National Cheng Kung University, Taiwan. hcli@mail.ncku.edu.tw

Frederick H. Wu. University of North Texas, USA. wu@unt.edu

\begin{abstract}
This study examines the economic consequences of internet financial reporting (IFR) in Taiwan. The results show that the stock prices of IFR firms change more quickly than those of the non-IFR firms using Akaike's (1969) Final Prediction Error (FPE) methodology. Second, the results from the event study methodology show that the cumulative abnormal returns of the firms with IFR are significantly higher than those of the firms without IFR. Lastly, the results indicate that firms with a higher degree of information transparency yield a higher abnormal return on their stock prices.
\end{abstract}

Keywords: Internet Financial Reporting (IFR), Information Content, and Information Diversity.

\section{INTRODUCTION}

With the rapid development of internet technologies, communications through the internet have been adopted as an essential tool to provide information characterized with pervasiveness, borderless-ness, real-time, low-cost, and high-interaction (Ashbaugh et al., 1999; Debreceny, et al., 2002) as well as with integration of text, figures, images, live pictures, and sounds (Debreceny et al., 2002). These characteristics, summarized in three words: diversity, timeless, and unlimited access, have transformed the internet into an important reporting medium (Verity, 1994) through which information about firm performance can reach all the potential global investors, in addition to the traditionally 
interest-vested parties such as creditors, stockholders, and analysts (Ashbaugh et al., 1999).

In view of the spread of internet financial reporting (IFR) by firms all over the globe, some regulators and standards-setting bodies, including stock exchanges, have begun to examine IFR in regards to its disclosure content, format, frequencies, etc. in order to consider the necessity of accounting and auditing standards related to IFR. In August 2000 , the SEC made a pronouncement that all public companies were recommended to make all legally-mandated information about performance to all interested parties at the same time. Companies should not favor selected customers with selected information. In other words, creditors, stockholders, analysts and investors all should have equal opportunities to access information on the internet. This announcement should have prompted more and more firms to deploy IFR to avoid any discrimination of information sharing. However, firms have been given free license as to how and what to disclose (FASB, 2000).

The voluntary nature of information provided on the internet by the public companies has led to non-uniformity in their disclosures (FASB 2000; IASC 1999). The diversity of IFR creates inconsistency on information completeness, comparability and reliability (Ashbaugh et al., 1999; Debreceny et al., 2002). In particular, equal accessibility by information users has become a major issue when there exists a gap between the time firms disclose financial information on the internet and the time they file financial reports with the SEC. Incomplete or selective financial reporting through the internet is expected if companies consider IFR as a supplement to the traditional financial reporting.

The IFR situation among firms in Taiwan is very much the same as the situation in the U.S. and other countries in the world. The Taiwan Accounting Standards Board and the Taiwan Securities Exchange (TSE) have not pronounced any regulations governing IFR and, therefore, firms have a great freedom in choosing how and what information to disclose on the internet. More importantly, there exists a time gap between a firm's filing of financial reports with the TSE and the time the TSE makes them available to the public. For those IFR firms, however, the disclosure of quarterly or annual reports on their websites occurs on the date of filing with the TSE. This raises a crucial research question: Does internet financial reporting (IFR), in its current state, affect the investors' investment decisions? If it does, to what extent does IFR impact the return from investment in stocks? We studied the case of Taiwan with the understanding that the market-based economy and the modus operandi of the stock exchange in Taiwan is similar in nature to other market-based economies around the world. Under this 
assumption we believe the conclusions derived from this study could be applied to explain the behavior of internet practices found in other similar economies.

Answers to the above questions are not easy since firms have not been uniformly disclosing information with regard to information content, disclosure format, and report frequency. The diversity of information disclosed makes it difficult to ascertain the contributions of internet technologies as far as financial reporting is concerned. More specifically, IFR has opened up a new research domain for accounting and finance scholars interested in understanding how the current state of the art in IFR may have influenced investor decisions. Although there are abundant research studies on IFR, none was found to have focused on the relationships between a firm's stock prices and their internet financial reporting.

Two different research models are adopted to examine the impact of IFR practices on Taiwanese firms' stock performance. First, using Akaike's (1969) Final Prediction Errors (FPE) methodology, we compare a sample of 101 Taiwanese firms with websites to disclose information to a matched sample of 101 Taiwanese firms without websites as the reporting medium between the time period of March 29 and April $2^{\text {nd }}$ of 2002. We find that the stock prices of firms with the IFR practice fluctuate faster than those of the firms without the IFR practice. In addition, we find that the stock prices of IFR firms disclosing more information on their websites fluctuate faster than those of the IFR firms disclosing less information on their websites.

Second, we use an event methodology to test whether the firms with IFR practices experience higher abnormal returns than firms without the IFR practices. In addition, we also test whether the IFR firms with higher information transparency as proxied by high level and large scope of information disclosed on their websites experience higher abnormal returns than those IFR firms with low level and small scope of information disclosed. Our findings show that the abnormal returns of the stock prices of those firms with IFR are significantly higher than those of the firms without IFR between day 2 and day 5 of the event period. In addition, IFR firms with higher information transparency have higher abnormal returns than those IFR firms with lower information transparency. Moreover, we also find that the market in Taiwan does not seem to respond to the website disclosure as fast as the efficient market theory would have predicted. We suggest that the market in Taiwan was not accustomed to use internet as a source of information for evaluating equity stocks during the period of our study. As the market understands internet as a timely information disclosure medium, it is possible that the market will respond to website disclosure faster. However, this is an empirical question outside of the scope of the current study, and is worth further investigation in future research endeavors. 
This study contributes to the IFR literature in twofold. First, this study contributes to the literature by examining the impact of IFR through the information users' perspective. Prior studies of IFR focus on the information providers' concerns. This is the first study, to our knowledge, focusing on the information users' concerns. Second, taking the information users' perspective, this study provides empirical evidence on the impact of IFR, and of the extent and scope of information disclosed via IFR on equity valuation.

The remainder of the paper is organized as follows: Section II presents a review of past research and points out the logic behind the undertaking of this research project. Section III presents the theoretical foundations of the theory formulated in five hypotheses. Section IV describes the research methodology. Section V presents the results of our analysis and Section VI concludes with a summary our findings.

\section{LITERATURE REVIEW}

In this section, we provide a summary of the existing IFR literature. Ashbaugh et al. (1999) investigate whether there is an enhancement of the information value through IFR. They conclude that firms view IFR as a tool for effective communication with customers and stockholders, and that profitable firms tend to adopt IFR. Craven and Marston (1999) study large companies' IFR in Great Britain and conclude that IFR is positively related to the size of firms expressed in terms of assets, but not related to industry types. Using public companies in the Austria Stock Exchange as their sample, Pirchegger and Wagenhofer (1999) investigate the qualities of IFR and conclude that the qualities are positively related to firm size expressed in terms of stock ownerships or firms' capitalization values.

Ettredge et al. (2002a) study the factors affecting firms' decision to disclose financial reports filed with the SEC as well as the factors driving firms' voluntary disclosures. Firm size, according to their findings, largely explain their disclosures of the same financial reports through the internet as the one filed with the SEC, and the size and reputation of a firm have a positive relationship with voluntary disclosures of all other information.

Debrecency et al. (2002) study 660 companies in 22 different countries and conclude that firm sizes, information technologies and companies listed on the NY Stock Exchange are the main factors to account for the adoption of IFR. Xiao et al. (2004) analyze the factors underlying Chinese companies' voluntary adoption of internet-based financial reporting, as well as their extent of disclosure. Factors identified as being relevant to voluntary disclosure choices in the more advanced market economies are included. In addition, theories on innovation diffusion and voluntary disclosure are used to generate hypotheses about factors specific to the Chinese context, such as type of auditor, foreign 
listing, different classes of stock ownership, and government regulations. Findings from the largest 300 Chinese companies confirm the proposition that firms' internet-based disclosure choices are responsive to specific attributes of their environment.

There is an abundant literature in the area of IFR reporting practices. Larrán and Giner (2002) examine the IFR practices of companies listed on the Madrid Stock Exchange. Their results are consistent with prior findings that size is a main factor for the quality and the level of financial information disclosed on the internet. Lybaert (2002) examines the reporting behavior of the entire set of Dutch listed companies on the AEX stock exchange as of the first two weeks of July 2000. Though reporting via internet seems to be an established fact, the author finds considerable variations on the quality of reporting completeness and web technology utilization among Dutch listed firms.

Furthermore, the author finds that reporting behavior within a single sector is more or less homogeneous than that of all companies of the sample. The author attributes such phenomenon to the followers' effect of wishing to keep pace with the competitors. Using the largest 20 companies in each European Union (EU) country, Bonsón and Escobar (2002) document the different information disclosed on the internet by the leading EU countries and examine the relationship between the extent of the voluntary disclosure on internet and size, country and industry sector. They conclude that these three factors significantly impact the level of voluntary disclosure on the internet. Allam and Lymer (2003) examine the online reporting practices of the 50 largest companies in U.S., U.K, Australia, Canada, and Hong Kong at the end of 2001 and in early 2002. They note that companies are applying emerging technologies for internet reporting, and more companies are disclosing financial information on the web.

With respect to the level of IFR disclosure, they find that UK, U.S. and Canada have higher level of disclosure, but do not find an association between size and level of disclosure of these countries with the exception of Australia. Lodhia et al. (2004) document a research study on corporate reporting through the internet by Australian companies.

The findings suggest that while corporate reporting through the internet is emerging in Australia, current practices did not utilize the full potential of the internet to disclose information to stockholders. And only limited evidence is found of changes in the reporting practices by companies prompted by the internet technology. Laswad et al. (2005) examine the voluntary IFR practices of municipalities in New Zealand. Six variables associated with voluntary disclosures are examined: size, leverage, municipal wealth, press visibility, political competition, and types of local municipalities. Results indicate that leverage, municipal wealth, press visibility, and types of local municipalities 
are associated with the IFR practice of local municipalities in New Zealand. In a more recent study of London-listed companies, Abdelsalam, Bryant amd Street (2007) shows that the comprehensiveness of IFR of London-listed companies is associated with corporate governance measures, such as analyst following, director holding, director independence and CEO duality after controlling for size, profitability, industry, and high growth/intangibles.

Ettredge et al. (2002b) study the timeliness of IFR by comparing the delay between the dates of filed annual reports with the SEC and the dates that they are posted on their corporate websites. The study concludes that profitability and information disclosure formats of firms are negatively related to the delay in their information disclosures on the internet. On the other hand, the delay in earnings announcement and the establishment of a linkage to the SEC's EDGAR are positively related to the delay in firms' IFR. More recently, Ezat and El-Masry (2008) examine the impact of corporate governance on the timeliness of IFR by the Egyptian companies listed on the Cairo and Alexandria Stock Exchange. They find a significant association between the timeliness of IFR and firm size, type of industry, liquidity, ownership structure, board composition and board size.

Ettredge et al. (2001) undertake a project to examine the investor relations directors' perceptions of financial information disclosed on the internet and they find that thirtyeight percent (38\%) of information provided through IFR is related to accounting and $30 \%$ related to finance, and that larger companies tend to disclose more information. As to the perceptions of the investor relations directors about IFR, they find that the directors consider the use of IFR cost-effective in creating goodwill with investors and that they have a proclivity to trying new technologies and to employing the website as a strategically integral part of a firm's communication with investors.

As summarized above, past IFR studies outside Taiwan focus on the informationproviders' concerns rather than the information-user's concerns. Studies of IFR in the context of Taiwan are very much the same as those outside of Taiwan. Chu (2001) investigates IFR practices in Taiwan and discovers that firms tend to disclose historical information and that the size and profit of a firm are positively related to IFR. Yan and Tseng (2001) report similar results as in Chu (2001)

Although there are abundant research studies on IFR as summarized above, none is found to have focused on the relationships between a firm's stock prices and their internet financial reporting. None of the studies cited above attempt to answer the question we pose earlier. Thus, taking the users' perspective, our study attempts to answer the following three specific questions: 
(1) Does the information that is provided to the public through the internet by a firm cause its stock price to change faster than the stock price of a firm that does not have a website to do the same?

(2) Does a different degree of information disclosure on the internet by a firm cause its stock price to change at a different pace?

(3) Does the degree of IFR practices by a firm have a significant impact on the return of its stock?

\section{THEORETICAL FOUNDATION AND HYPOTHESES}

In this section, we develop hypotheses to test the stock market reaction to IFR by Taiwanese firms. The theory of efficient markets would predict that if markets are efficient then, in equilibrium, stock prices only respond when useful information is entering the market (Beaver 1968; Ball and Brown 1968). A generally-accepted theory with regard to the characteristics of useful information is that information, if useful, must be relevant to the decision to be made and that information must be provided timely to be relevant to decision-makers. (FASB 1980, 2000). In the investment market, a piece of useful information would normally cause investors to take actions that will lead to redistribution of the investment rewards and so, it will topple and reset the equilibrium of the market. Beaver (1968), using this concept of information usefulness, theorized that if the information of a firm's profit announcement could lead to the change of the firm's stock price, it, then, has the information content, signaling useful information to investors. Moreover, information must be timely to be relevant, and consequently, timeliness is a necessary dimension of useful information. What, then, is considered timely on the investment market? Beaver (1968) defined timely in terms of two elements, reporting delay and reporting interval. The shorter is the delay and the interval, the timelier is the information.

Furthermore, a considerable amount of literature has emerged in the last few decades which examines voluntary corporate financial reporting (e.g., Easley and O'Hara 2004; Easley et al., 2002; Frankel et al. 1999; Sengupta 1998; Botosan 1997; Yeo and Ziebart 1995; Welker 1995; Leftwich et al. 1981). The literature suggests that the corporation benefits with voluntary disclosure - reduce cost of capital, agency costs or contracting costs, and enhance firm value. Voluntary disclosures on company's activities reduce information asymmetry between the investors and the management about a firm's financial condition and results of operations in the corporate environment. In view of the empirical evidence suggested by prior research, IFR, on the voluntary basis, should provide greater information value to investors and should spell more impact on stock prices. Once information is disclosed through IFR, it is instantaneously available to all 
investors, thereby reducing information asymmetry and shortening information accessibility delay.

Traditionally on the Taiwan stock market, monthly financial information of the firm is not available until it was delivered to the TSE that, in turn, makes it available to the public. Thus, if a firm does not disclose information on the internet at the same time as it delivers the information to the TSE, there will be a longer time interval for investors to receive the information. That also means a longer information delay to investors. Thus, shortening time intervals in information delivery leads to shortening decision making cycle by investors, thereby quickening the pace of change in stock prices. Comparatively speaking, the time intervals for firms with IFR and firms without IFR in delivery of financial information to investors are different, and therefore, the response speeds of the stock prices of the IFR firms will be different from those of the non-IFR firms. Hypothesis 1 is posed as follows:

Hypothesis 1 (H-1): Stock prices change faster in those firms with IFR than stock prices in those firms without IFR.

The signaling theory points out that without information transparency between buyers and sellers, buyers will haggle with their sellers on prices to the point that prices are so low that sellers have to lower qualities of products to sustain a profit. This economic behavior eventually leads to the disappearance of sellers with high-quality products--a phenomenon called adverse selection (Spence 1973). To avoid this situation on the investment market, Beaver (1968) claimed that companies would disclose as much information as possible so that investors were able to differentiate good companies from bad ones. Voluntarily disclosing additional information, financial and non-financial, on the internet, creates greater information transparency. Information transparency reduces information asymmetry between owners (or investors) and management which in turn affects the cost of equity capital (Botosan 1997), cost of debt capital (Sengupta 1998), firm values (Frankel et al. 1999) and market liquidity (Welker 1995). Hypothesis 2 is posed as follow:

Hypothesis 2 (H-2): The abnormal return of the stock price of a company that practices IFR will be higher than that of a company that does not practice IFR.

Ashbaugh et al. (1999) indicate that an important element of IFR is the degree or quantity of disclosure. The higher the degree of information disclosure in quantity is, the greater the impact of the disclosure on investors' investment decisions is. Easley and O'Hara (2004) conclude in their study that investors given more relevant information achieve a higher return on their investments. They demonstrate how the quantity and quality of information affect stock prices in equilibrium. Hirst and Hopkins (1998) 
demonstrate that a higher level of transparency is achieved when a comprehensive income statement is presented to stockholders, thereby enabling analysts to evaluate earnings management and the fair value of a firm's stock. Moreover, information disclosure channels may be widened in scope on the internet by linking several websites into one integrated reporting system. Each website in an extended internet provides information about the local (a subsidiary, division, or strategic business unit) performance. Thus, an extended network provides not only information about the aggregate performance of the entity, but also the performance of individual business units. Thus three hypotheses are posed as follows:

Hypothesis 3 (H-3): Stock prices change faster in those firms that provide more information than stock prices in those firms that provide not as much information, on the internet.

Hypothesis 4 (H-4): The abnormal return of the stock of a company that provides a greater degree of information disclosure will be higher than that of a company that provides a less degree of information disclosure, on the internet.

Hypothesis 5 (H-5): The abnormal return of the stock of a company that provides a large scope of information disclosure will be higher than that of a company that provides a small scope of information disclosure, both through IFR.

\section{RESEARCH METHODOLOGY}

Different models were applied to test different hypotheses. The models are explained below.

\section{The Speed of Stock Price Responses to Internet Financial Reporting}

We tried to select time periods appropriate for testing each of the five hypotheses. In order to test $\mathrm{H}-1$ and $\mathrm{H}-3$, i.e., the response of stock prices to the disclosure of information on the websites, the test period began on the day when new financial information was filed with the TSE and also posted on the company's website - called the first transaction event date, and continued with transaction events for the next 49 days, giving a total of 50 observations. Then, final prediction errors based on autoregressive modeling (Akaike, 1969), were calculated to analyze the data. The autoregressive model is expressed as follows:

$$
P_{t}=\alpha_{0}+\sum \alpha_{i} P_{t-i}+\varepsilon_{t}
$$

where:

$P_{t}:$ the stock price at time $t$,

$P_{t-i}:$ the stock price at time $t-i$. 
According to Fama (1970), efficient market means that the price of a stock will reflect all information available at any time. It implies that the immediate past price will not affect the current price. In reality, however, the time when information is available and the time when investors actually receive the information are not simultaneous and therefore, the stock price does not reflect all information available at any time. This also means that the current price of a stock is partially affected by the immediate past price. In general, a short time interval, in which the current stock price changes to reflect the immediate past price, indicates fast absorption of the information on the stock market. For this study, we adopted Akaike's (1969) minimum FPE to examine the lag length in which the current price of a stock was affected by its past price, thereby enabling us to determine the speed by which information provided through IFR is reflected in the stock price. If the lag length is shorter for the stock price of a firm with IFR than that for the stock price of a firm without IFR, then, IFR does provide useful information. Akaike's FPE is shown as follows:

$$
F P E=\frac{T+g+1}{T+g-1} X \frac{S S E}{T}
$$

where:

$\mathrm{T}=$ no. of days of past stock prices included in equation 1 ,

$\mathrm{g}=$ the appropriate lag length for dependent variable, expressed in days (between 1 and 50),

SSE $=$ sum of square errors from equation 1.

By auto-regressing Equation 1, we find answers for $\mathrm{g}$ and SSE. Equation 1 is autoregressed with $\mathrm{t}=1$ (day) until $\mathrm{t}=\mathrm{k}$ (days) when FPE is found to be the minimum.

\section{The Relationships between IFR and Abnormal Returns of Stock Prices}

To test $\mathrm{H}-2, \mathrm{H}-4$, and $\mathrm{H}-5$, we adopted the "event" investigation approach. The disclosure of financial and non-financial information on the internet is treated as an event for this study. As stated earlier, the purpose of this study is to investigate whether this event has a significant impact on the stock price. The impact was measured in terms of the abnormal return during the event period (which will be explained later). In testing H2 , if the abnormal return of IFR firms is significant whereas the non-IFR firms exhibit no evidence of abnormal return, then IFR has information content for IFR firms. Furthermore, in testing H-4 and H-5, the abnormal return is treated as the dependent variable in the regression model and the degree of the disclosure of IFR and the scope of the disclosure are treated as independent variables. Mikkelson and Partch (1986) and 
Chan et al. (1990) also used abnormal returns as a substitute for the impact on stock prices in their studies.

\section{Sample Selection}

Data is collected from two sources: web sites of business firms and the database of the Taiwan Economics Journal.

\begin{tabular}{|c|c|c|c|}
\hline Industry & $\mathbf{N}$ & $\begin{array}{c}\text { Firms Establishing } \\
\text { Web-sites }\end{array}$ & $\begin{array}{c}\text { Firms Using Web-sites to Disclose } \\
\text { Financial Information }\end{array}$ \\
\hline Cement & 8 & $\begin{array}{c}5 \\
62.50 \%\end{array}$ & $\begin{array}{c}3 \\
37.50 \%\end{array}$ \\
\hline Food & 23 & $\begin{array}{c}17 \\
73.91 \%\end{array}$ & $\begin{array}{c}6 \\
26.09 \%\end{array}$ \\
\hline Plastics & 20 & $\begin{array}{c}17 \\
85.00 \%\end{array}$ & $\begin{array}{c}8 \\
40.00 \%\end{array}$ \\
\hline Textile & 54 & $\begin{array}{c}36 \\
66.67 \%\end{array}$ & $\begin{array}{c}5 \\
9.26 \%\end{array}$ \\
\hline Electric machinery & 31 & $\begin{array}{c}31 \\
100.00 \%\end{array}$ & $\begin{array}{c}10 \\
32.26 \%\end{array}$ \\
\hline $\begin{array}{l}\text { Electric equipment \& } \\
\text { cable }\end{array}$ & 15 & $\begin{array}{c}13 \\
86.67 \%\end{array}$ & $\begin{array}{c}5 \\
33.33 \%\end{array}$ \\
\hline Chemical industry & 28 & $\begin{array}{c}22 \\
78.57 \%\end{array}$ & $\begin{array}{c}6 \\
21.43 \%\end{array}$ \\
\hline Glass & 5 & $\begin{array}{c}4 \\
80.00 \%\end{array}$ & $\begin{array}{c}2 \\
40.00 \%\end{array}$ \\
\hline Papermaking & 7 & $\begin{array}{c}4 \\
57.14 \%\end{array}$ & $\begin{array}{c}2 \\
28.57 \%\end{array}$ \\
\hline Steel & 21 & $\begin{array}{c}15 \\
71.43 \%\end{array}$ & $\begin{array}{c}5 \\
23.81 \%\end{array}$ \\
\hline Rubber & 9 & $\begin{array}{c}9 \\
100.00 \%\end{array}$ & $\begin{array}{c}1 \\
11.11 \%\end{array}$ \\
\hline Automobile & 4 & $\begin{array}{c}3 \\
75.00 \%\end{array}$ & $\begin{array}{c}2 \\
50.00 \%\end{array}$ \\
\hline Electron & 195 & $\begin{array}{c}189 \\
96.92 \%\end{array}$ & $\begin{array}{c}88 \\
45.13 \%\end{array}$ \\
\hline Construction & 35 & $\begin{array}{c}21 \\
60.00 \%\end{array}$ & $\begin{array}{c}5 \\
14.29 \%\end{array}$ \\
\hline Transportation & 17 & $\begin{array}{c}15 \\
88.24 \%\end{array}$ & $\begin{array}{c}7 \\
41.18 \%\end{array}$ \\
\hline Tourism & 6 & $\begin{array}{c}4 \\
66.67 \%\end{array}$ & $\begin{array}{c}1 \\
16.67 \%\end{array}$ \\
\hline Banking & 48 & $\begin{array}{c}48 \\
100.00 \%\end{array}$ & $\begin{array}{c}42 \\
87.50 \%\end{array}$ \\
\hline $\begin{array}{l}\text { Trade\& general } \\
\text { merchandise }\end{array}$ & 10 & $\begin{array}{c}8 \\
80.00 \%\end{array}$ & $\begin{array}{c}2 \\
20.00 \%\end{array}$ \\
\hline Other & 36 & $\begin{array}{c}29 \\
80.56 \%\end{array}$ & $\begin{array}{c}6 \\
16.67 \%\end{array}$ \\
\hline Total & 572 & $\begin{array}{c}490 \\
85.66 \%\end{array}$ & $\begin{array}{c}206 \\
36.01 \%\end{array}$ \\
\hline
\end{tabular}

Table 1: The Distribution of Firms in Terms of the Establishment of the Web-site and the Disclosure of Financial Information on the Web-site. 
The former entails the observation of a firms' reporting on the internet. The later provided data pertaining to stock prices, cumulative abnormal returns, and market investment portfolio returns of the firms listed on the Taiwan Stock Exchange. Sample period of the study is between March $29^{\text {th }}$ and April $2^{\text {nd }}$ of 2002. Firms in Taiwan usually file their mandatory financial reports with the Taiwan Stock Exchange (TSE) during this period. Of all 572 companies listed on the TSE (as of March 29, 2002), there were 490 $(85.66 \%)$ that had established websites on the internet, but only 206 of them provided financial and non-financial information on the websites. The search for a firm's web site(s) was made primarily through internet search engines of such as Google, Yahoo, the TSE, and others (Table 1).

Firms that could not be identified with the existence of a web site or did not disclose financial data via their websites were contacted through phone calls or emails to confirm the fact that they did not have internet financial reporting. We excluded 32 firms from the sample for not timely posting the financial and non-financial information on their websites as soon as the filing with the TSE was complete. 26 firms were excluded for missing data from the database. Additional 23 firms with unstable $B$ for the periods before and after the event window are excluded. Lastly, 24 firms which we unable to pair with the matched firms are removed from the sample. Of 206 firms disclosing financial and non-financial information on their websites, only 101 firms were included in the final sample of the experimental group. Table 2 shows selection procedure for the 101 IFR firms

\begin{tabular}{l|c|}
\hline Selection process & Experimental group \\
\hline $\begin{array}{l}\text { Firms disclosing financial information on their web-sites } \\
\text { Less: Firms without timely posting of information filed } \\
\text { with TSE }\end{array}$ & 206 \\
\hline $\begin{array}{l}\text { Firms without available data from TEJ database } \\
\text { Firms with significantly unstable } \beta \text { for the periods } \\
\text { before and after the event window }\end{array}$ & $(32)$ \\
\hline Firms without matched firms & $(23)$ \\
\hline Firms selected & $(24)$ \\
\hline
\end{tabular}

Table 2. Sample selection

And Table 3 shows the distribution of these 101 IFR firms among 19 industries. Though more than half of the firms in the experimental group consist of firms from the electronic industry and the banking industry consists of $8 \%$ of the sample, the additional sample selection criteria discussed above exclude a higher percentage of electronic companies and banking institutions from our final sample compared to that of companies excluded from other industries.

We adopt Rice's (1978) research methodology of experimental vs. control group design. The former was made up of those firms with IFR and the latter without IFR. Both 
groups of firms file reports with the TSE by the due date, but only the experimental group releases the information faster to the public via the internet. The implementation of this control group vs. experimental group methodology should reveal some systematic differences in stock prices of these two groups around the time that the experimental group discloses same information filed with the TSE on the internet. Holding all other things constant, this study aimed at investigating whether or not IFR would have a significant impact on firms' stock prices.

\begin{tabular}{|l|c|}
\hline Industry & Experimental group \\
\hline Cement & 2 \\
\hline Food & 4 \\
\hline Plastics & 5 \\
\hline Textile & 2 \\
\hline Electric machinery & 7 \\
\hline Electric equipment \& cable & 4 \\
\hline Chemical industry & 2 \\
\hline Glass & 1 \\
\hline Papermaking & 1 \\
\hline Steel & 3 \\
\hline Rubber & 0 \\
\hline Automobile & 2 \\
\hline Electron & 46 \\
\hline Construction & 3 \\
\hline Transportation & 3 \\
\hline Tourism & 1 \\
\hline Banking & 8 \\
\hline Trade \& general merchandise & 2 \\
\hline Other & 5 \\
\hline Total & $\underline{101}$ \\
\hline
\end{tabular}

Table 3. Industry composition

The Experimental Group: The selection of firms to be included in this group was based on the following criteria:

1. Between March 29, 2002 and April 2, 2002, firms had a web site to which investors could access,

2. Both financial and non-financial information of the firms were disclosed during the event period at the same time the firms file with the TSE, and

3. The system risks of the firms were stable before and after the event.

Since this study used the market model to determine the abnormal return, the stability has a significant impact on the empirical results of this study. If the coefficient was not stable, it will lower the credibility of prediction and commingle the system and non-system risks (Hays and Upton, 1986). Furthermore, to analyze market efficiency based on the market error term will have doubtful results. Thus, it was absolutely essential that the system risk must be examined in terms of its stability before and after 
the event of the disclosure of financial information on the internet. This study adopted Chow's test (1960) to examine the stability of the system risk.

The Control Group: This group consists of firms that did not establish a web site on the internet or firms that had a web site but did not post the information filed with the TSE on their websites between March 29, 2002 and April 2, 2002. Two different sampling methods utilized in similar prior studies were adopted: random sampling and pairs-matching sampling. Although little differences were found empirically from the results of using these two methods, most researchers tended to use the matching approach. For example, Shivakumar (2000) used the pair-matching sample to investigate the announcement of quarterly profits and abnormal returns. The matching criteria for our study were: (1) same industries, (2) approximately equal capitalization during the observation period and (3) same TSE filing date as the matched firm in the experimental group.

\section{Statistical Analysis}

In this section, we will explain the statistical analysis made regarding the differences of IFR impact on stock prices between the experimental group and the control group.

Testing of Information Content's Impact ( $H-1$ and $H-3)$ : T-tests, similar to the tests used by Rice (1978), were applied to investigate the differences of the response speeds of stock prices to the event of IFR between the Experimental Group and the Control Group as well as within the Experimental Group partitioning based on the degree of disclosures. If IFR provides timely and relevant information to investors, then the number of days in which price change takes place for the experimental group should be smaller than that of the control group. Moreover, if IFR firms use the internet to disseminate information to their stakeholders, we expect to see a faster response of stock prices for IFR firms with higher degree of disclosure than IFR firms with lower degree of disclosure. For this study, the day on which a company disclosed financial information on the internet is considered the event day and the event day plus the following 49 days (50 days in total) are treated as the observation period. Note that the event day was identified for this study through correspondence by email or phone calls and that financial reporting is done once only during the event period. Auto-regression and the final prediction error (PFE) were used to test $\mathrm{H}-1$ and $\mathrm{H}-3$.

Testing of the Abnormal Returns $(\mathrm{H}-2, \mathrm{H}-4$ and $\mathrm{H}-5)$ : Treating financial reporting on the internet as the investigation event, this study attempts to determine whether this event has significant impact on the stock price, thereby generating an abnormal return. To measure the abnormal return of a stock, we adopted the efficient market research methodology suggested by Fama et al. (1969). We compute the cumulative abnormal 
returns (CAR) for an 11-day event window that is 5 days before and 5 days after the posting of financial and non-financial information on the internet. Rice (1978) used T-test to examine the difference of the cumulative abnormal returns of the stocks between the experimental group and the control group. This study also used T-tests for examining differences of the abnormal returns between the experimental group and the control group.

\section{Measurements of the Degree of Information Disclosure and the Scope of Internet Reporting}

The method for measuring the degree of information disclosure was adapted from Ettredge et al. (2001) by modifying it to include basic profile and operational items and by using a 4-point weighted scale system to assign points to each disclosure item. The checklist of potential financial and non-financial disclosure items is shown in Table 4.

\begin{tabular}{|c|c|c|}
\hline Information Disclosure Type & Measurement Items & Score \\
\hline \multirow{7}{*}{ Basic Profile } & 1. Firm profile $\&$ history & 1 \\
\hline & 2.Business cultures, operation policies \& strategies & 1 \\
\hline & 3.Products and services information & 1 \\
\hline & 4.Firm's organization and management team & 1 \\
\hline & 5. Human resources information & 1 \\
\hline & 6. Investment \& conglomerate & 1 \\
\hline & 7. Contact information & 1 \\
\hline \multirow{3}{*}{ News } & 1.Industry information & 1 \\
\hline & 2.Products and operations information & 1 \\
\hline & 3 Finance-related news & 1 \\
\hline \multirow{3}{*}{ Operational Items } & 1. Operation profile & 1 \\
\hline & 2. Operation objective \& outlook & 1 \\
\hline & 3. Industry analysis \& related research report & 1 \\
\hline \multirow{11}{*}{ Financial Information } & 1 Selected financial information & 1 \\
\hline & 2. Condensed quarterly financial reports & 2 \\
\hline & 3. Condensed semi-annual financial reports & 2 \\
\hline & 4. Condensed annual financial reports & 2 \\
\hline & 5. Complete set of financial reports (quarterly) & 3 \\
\hline & 6. Complete set of financial reports (semi-annual) & 3 \\
\hline & 7. Complete set of financial reports ( annual) & 3 \\
\hline & 8. Annual board of directors report & 4 \\
\hline & 9.Monthly operational revenue information & 1 \\
\hline & 10.Financial analysis & 1 \\
\hline & 11.Financial forecast & 1 \\
\hline \multirow{4}{*}{ Stock Information } & 1.Historical stock price and dividend information & 1 \\
\hline & 2.Dividend policies & 1 \\
\hline & 3.Current stock price information & 1 \\
\hline & 4.Stock agent information & 1 \\
\hline
\end{tabular}

Table 4. Measurement items of the Degree of information disclosed

A weighted scale system was adopted to highlight the importance of various information content disclosed via company's website for investors decision making. The 
basic profile of a firm, news about a firm or operational information of a firm was assigned 1 point.

In general, simplified quarterly, semi-annual or annual financial reports provide less financial information for decision making than a complete set of financial reports (quarterly, semi-annual or annual), therefore, we assigned 2 points for these simplified reports and 3 points for the complete set of financial reports. Annual reports by the board of directors not only include the complete set of financial reports, but also information about business strategies of the subsidiary companies and major divisions and their goals and business plans. Thus, we assigned 4 points for the annual board of directors' report. Total possible points ranged from 0 to 40 .

The scope of IFR is defined as the extent by which the firm's central website is linked to other websites within or outside of the firm to form an inter- or intra-firm website structure. The purpose of this linkage is to provide supplementary information. The other websites include: (1) the Taiwan Stock Exchange, (2) subsidiary companies or major divisions, (3) strategic business units, and (4) up-stream companies such as suppliers and manufacturers, and down-stream companies such as wholesalers, retailers, and other customers. For measuring the scope of internet reporting, the method used by Ashbaugh et al. (1999) and Craven and Marston (1999) was adopted. Each type of linkage is assigned one point and the total possible points for a firm are four points (refer to Table 5).

\begin{tabular}{|l|c|}
\hline Measurement Items & Score \\
\hline 1. Link firm's website to stock market station of Taiwan Stock Exchange & 1 \\
\hline 2. Link firm's website to major divisions or subsidiary companies & 1 \\
\hline 3. Link firm's website to strategic business units & 1 \\
\hline 4. Link firm's website to up-stream and down-stream companies & 1 \\
\hline
\end{tabular}

Table 5: The Measurement Items of the Scope of Internet Reporting

\section{RESULTS OF ANALYSIS}

In order to test Hypothesis 1, the experimental group was tested against the control group, using the techniques of auto-regression and final prediction errors. As indicated in Table 6, all the statistics (the average, the median, and the maximum) indicate that it took fewer days for stock prices to change in the experimental group. In other words, the stock prices of the companies in the experimental group responded to IFR faster than that of the control group. The second part of Table 6 supports the above finding with a one-tail Ttest $(\mathrm{p}=0.0016)$, thereby accepting the first hypothesis that the disclosure of financial information on the internet by a company leads to faster response of its stock price than a company without the corresponding disclosure. 


\section{The Relationships between Extraordinary Returns of Stocks and Disclosure of Financial Information on the Internet}

In this section, we will first explain the event approach for collecting data and the statistical techniques used for data analysis. Finally, the results of the data analysis related to Hypothesis 2 are presented.

\begin{tabular}{|c|c|c|c|c|c|c|}
\hline \multicolumn{7}{|c|}{ Part I: Descriptive Statistics } \\
\hline & $\mathrm{N}$ & Mean & Median & Min & Max & Std. Dev. \\
\hline Experimental Group & 101 & 2 & 2 & 1 & 6 & 1 \\
\hline Control Group & 101 & 3 & 3 & 1 & 7 & 1 \\
\hline \multicolumn{7}{|c|}{ Part II: The T-test results } \\
\hline \multicolumn{7}{|c|}{$\begin{array}{l}\mathrm{T} \text { Value }=-2.9828 * * *, \mathrm{P}(\mathrm{T}<=\mathrm{t})=0.0016 \\
* * *: \text { Statistically significant at the } 1 \% \text { level. }\end{array}$} \\
\hline
\end{tabular}

Table 6: The Difference in Days between Experimental Group and Control Group of stock Price Reaction

The Event Methodology: This study adopts the event methodology for measuring abnormal returns. The event day is defined as the day when financial information was first disclosed on the internet between March 29 and April $2^{\text {nd }}, 2002$ by the 101 IFR firms. The event period is defined as the five (5) days before and after the event day. Stock prices were collected at the beginning and ending of the event period and also on the event day. The market model was first used to estimate the cumulative abnormal returns (CAR) for the experimental group and the control group. Then, the statistical Ttests were used to test any significant differences of the cumulative abnormal returns between the two groups. Two methods were used to calculate the differences of the abnormal returns between the two groups. The first method was to compare the average cumulative abnormal return of the experimental group as a whole on the day $\mathrm{t}(\mathrm{t}=(-5 \sim$ $+5)$ ) with the corresponding average CAR of the control group (refer to Column 5 of Table 7 and Figure 1). The second method was to first, pair companies from the two groups and then compute the average of the differences of the abnormal returns from individual pairs for day $\mathrm{t}(\mathrm{t}=(-5 \sim+5))$ (refer to Column 4 of Table 7 and Figure 1).

Column 2 of Table 7 indicates that the abnormal returns for the experimental group on the second through the fifth day following the event day,- the day of the disclosure of financial information on the internet,- were significantly different from zero while the corresponding abnormal returns for the control group were insignificant (refer to column 3 of Table 7). Furthermore, Column 4 of Table 7 displays that the abnormal returns of the experimental for the first through the fifth day, based on the approach of matching individual companies (Method 2 as described above), were significantly different from those of the control group at either .05 or .10 level. 


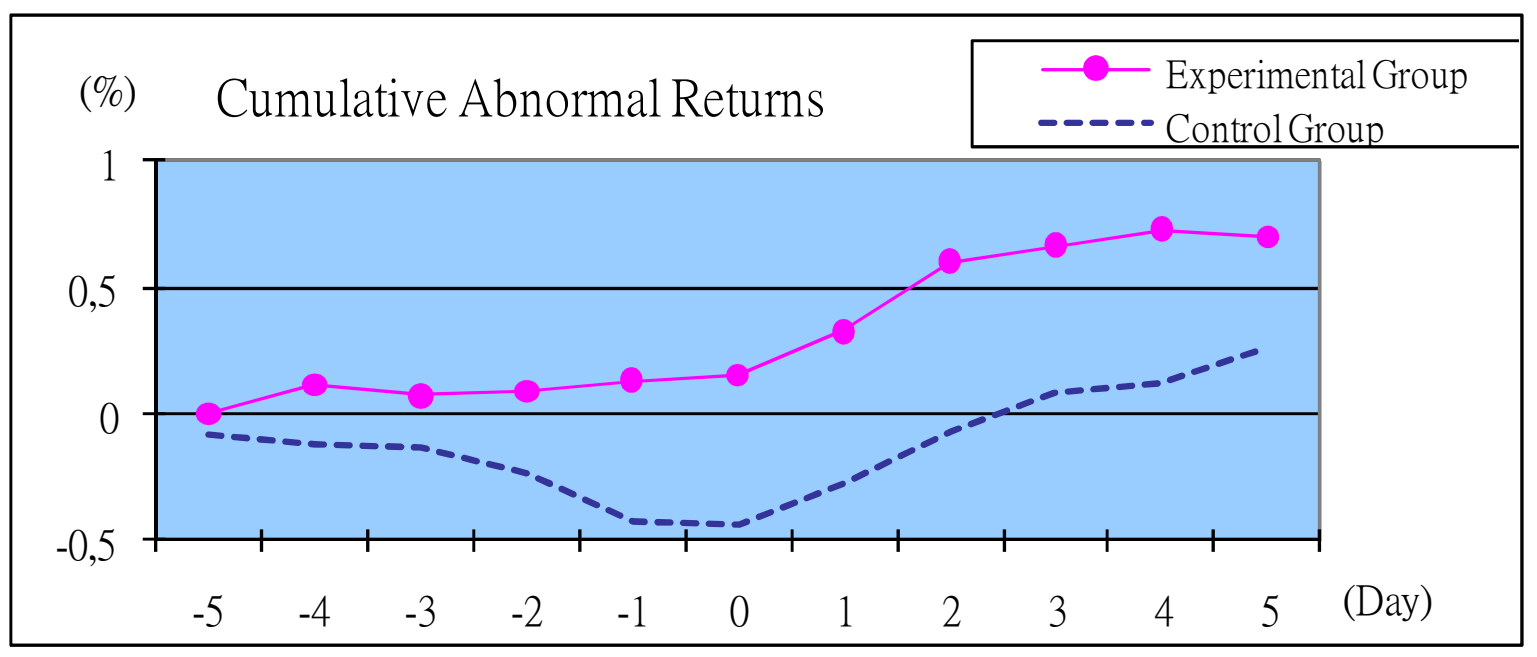

Figure 1. Abnormal Returns of the Experimental Group and the Control Group

Based on Method 1, the abnormal return of the experimental group was significantly different from that of the control group only for the second day after the event day.

\begin{tabular}{|c|c|c|c|c|}
\hline Day $\mathbf{t}$ & $\begin{array}{c}\text { Experimental Group } \\
\text { CAR }_{\text {t }} \\
\text { (T Value) }\end{array}$ & $\begin{array}{c}\text { Control Group } \\
\text { CAR }_{\mathbf{t}} \\
\text { (T Value) }\end{array}$ & $\begin{array}{l}\text { Method } 2 \\
\text { Mean of } \\
\text { CAR }^{\mathrm{a}} \\
\text { (T value) }\end{array}$ & $\begin{array}{l}\text { Method 1 } \\
\text { CAR }^{\mathbf{b}}{ }_{\mathbf{t}} \\
\text { (T Value) }\end{array}$ \\
\hline-5 & $\begin{array}{c}-0.0007 \\
(-0.0079)\end{array}$ & $\begin{array}{c}-0.0045 \\
(-0.0506)\end{array}$ & & $\begin{array}{c}0.0038 \\
(0.0293)\end{array}$ \\
\hline-4 & $\begin{array}{c}0.1145 \\
(0.7631)\end{array}$ & $\begin{array}{c}-0.0138 \\
(-0.1048)\end{array}$ & & $\begin{array}{c}0.1283 \\
(0.6426)\end{array}$ \\
\hline-3 & $\begin{array}{c}0.0733 \\
(0.3822)\end{array}$ & $\begin{array}{c}0.0134 \\
(0.1010)\end{array}$ & & $\begin{array}{c}0.0599 \\
(0.2571)\end{array}$ \\
\hline-2 & $\begin{array}{c}0.0881 \\
(0.4000)\end{array}$ & $\begin{array}{c}-0.1456 \\
(-1.0538)\end{array}$ & $\begin{array}{c}0.2337 \\
(1.01)\end{array}$ & $\begin{array}{c}0.2337 \\
(0.8988)\end{array}$ \\
\hline-1 & $\begin{array}{r}0.13 \\
(0.56\end{array}$ & $\begin{array}{c}-0.2360 \\
(-1.4417)\end{array}$ & & $\begin{array}{c}0.3670 \\
(1.2998)\end{array}$ \\
\hline 0 & $\begin{array}{r}0.15 \\
(0.58\end{array}$ & $\begin{array}{c}-0.2605 \\
(-1.3866)\end{array}$ & $\begin{array}{l}0.4 \\
(1 .\end{array}$ & $\begin{array}{c}0.4135 \\
(1.2869)\end{array}$ \\
\hline 1 & $\begin{array}{r}0.327 \\
(1.202\end{array}$ & $\begin{array}{l}-0.2 \\
(-1.1\end{array}$ & $\begin{array}{l}0.5 \\
(1 .\end{array}$ & $\begin{array}{c}0.5596 \\
(1.6522)\end{array}$ \\
\hline 2 & $\begin{array}{c}0.6048 \\
(2.0643)^{* *}\end{array}$ & $\begin{array}{l}-0.0 \\
-0.2\end{array}$ & $\begin{array}{c}0.6589 \\
(2.01)^{* *}\end{array}$ & $\begin{array}{c}0.6589 \\
(1.7529)^{*}\end{array}$ \\
\hline 3 & $\begin{array}{c}0.6645 \\
(2.0590)^{* *}\end{array}$ & $\begin{array}{c}-0.0191 \\
(-0.0701)\end{array}$ & $\begin{array}{l}0.6836 \\
(1.87)^{*}\end{array}$ & $\begin{array}{c}0.6836 \\
(1.6184)\end{array}$ \\
\hline 4 & $\begin{array}{c}0.7316 \\
(2.1167)^{* *}\end{array}$ & $\begin{array}{c}0.0204 \\
(0.0648)\end{array}$ & $\begin{array}{l}0.7112 \\
(1.84)^{*}\end{array}$ & $\begin{array}{c}0.7112 \\
(1.5205)\end{array}$ \\
\hline 5 & $\begin{array}{c}0.6996 \\
(1.8368)^{*}\end{array}$ & $\begin{array}{c}0.1917 \\
(0.5648)\end{array}$ & $\begin{array}{l}0.5079 \\
(1.22)^{*}\end{array}$ & $\begin{array}{c}0.5079 \\
(0.9957)\end{array}$ \\
\hline \multicolumn{5}{|c|}{$\begin{array}{l}\text { * Statistically significant at the } 10 \% \text { level, } \\
\text { ** Statistically significant at the } 5 \% \text { level. } \\
\text { a: } \mathrm{CAR}_{\mathrm{t}}=\text { the mean of the difference of the abnormal returns from individual pairs } \\
\text { for day } \mathrm{t}(\mathrm{t}=(-5 \sim+5)) \text { and } \mathrm{N}=101 \text {. } \\
\text { b: } \mathrm{CAR}_{\mathrm{t}}=\text { the difference between the average } \mathrm{CAR} \text { of the experimental group as a whole } \\
\text { and the average CAR of the control group as a whole on the day } \mathrm{t}(\mathrm{t}=(-5 \sim+5)) \text { and } \\
\mathrm{N}=101 \text {. }\end{array}$} \\
\hline
\end{tabular}

Table 7: Cumulative Abnormal Returns of the Experimental and Control Groups 
The reason for this difference between Method 1 and Method 2 may lie in the fact that the matching was done along the line of similar industries - which could provide better comparison between the two groups. Another reason is that taking the groups a whole to compute the average will lead to the compensation effect, i.e., positive fluctuations offset negative ones. Thus, a conclusion can be drawn that companies with the disclosure of financial information on the internet will lead to higher yield on the cumulative abnormal returns than those of companies without similar disclosure of financial information on the internet. Hypothesis 2 thus can be accepted.

Interestingly, the results consistently show that the cumulative abnormal returns of the experimental group or the difference in cumulative abnormal returns between the experimental and the control groups were not significant until the second day after the event day. One explanation for this interesting finding is that website financial disclosure is a new phenomenon in Taiwan, and investors may not be accustomed to this new reporting medium as employed by the IFR firms. As a result, the market does not respond to the information as soon as it is disclosed on the internet. As the market better understands internet as a timely reporting medium for financial information, it will react faster to the information disclosed via firm's website. A natural extension of the current study is to examine whether the market responds to subsequent website financial disclosures as soon as it is disclosed online.

The Degree of Information Disclosure: To test Hypothesis 3, we separated 101 companies in the experimental group into two subgroups: those with a total disclosure score above the average was designated as Experimental Group One (EG1) and those below the average designated as Experimental Group Two (EG2). The techniques of auto-regression and the final prediction errors were applied to test $\mathrm{H}-3$ and the results were presented in Table 8.

\begin{tabular}{l}
\begin{tabular}{|l|c|c|c|c|c|c|}
\hline Part I: Descriptive Statistics & N & Mean & Median & Min & Max & Std. Dev. \\
\hline Experimental Group 1 & 44 & 2 & 2 & 1 & 4 & 1 \\
\hline Experimental Group 2 & 57 & 3 & 2 & 1 & 6 & 1 \\
\hline Part II: The T-test results of experimental groups (1) and (2). \\
T Value= $=-2.3017 * *$. P(T<=t) $=0.0117$ \\
$* *$ Statistically significant at the 5\% level.
\end{tabular} \\
\hline
\end{tabular}

Table 8: The Difference in Days between Experimental Groups 1 and 2 of the Stock Price Reaction

Table 8 shows that the stock prices of EG1 took fewer days to respond to the disclosed financial and non-financial information on the internet as compared with EG2. The result of one-tail T-test $(\mathrm{T}=-2.3017, \mathrm{P}(\mathrm{T}<=\mathrm{t})=0.0117)$ shows that Hypothesis 3 can be accepted, which is that a higher degree of the disclosure of financial information on the internet by a company would prompt its stock price to change more quickly. On the 
other hand, the stock price of a company with a lower degree of the disclosure of financial information would take a longer time to respond to IFR.

The Relationship between the Cumulative Abnormal Returns and the Disclosure of Information on the Internet: In this section, we will analyze the relationships between the cumulative abnormal returns and the disclosure of financial information on the internet. The disclosure of financial information on the internet is defined in terms of (1) the degree of the disclosure of information on the firm's major internet site and (2) the scope of the internet reporting. Multiple-regression analysis is used to test the relationships.

Descriptive Analysis: Table 9 presents the descriptive statistics of the cumulative abnormal returns, the degree of internet disclosure of information, and the scope of internet reporting. The mean of the internet information disclosure was found to be 12.2574 with a maximum of 40 points appearing to indicate a low degree of information disclosure on the internet. The mean of the scope of internet reporting was 0.8812--which indicated that many companies did not link their web-sites to other web-sites.

\begin{tabular}{|l|c|c|c|}
\hline Variables & CAR & $\begin{array}{c}\text { The Degree of } \\
\text { Information } \\
\text { Disclosure } \\
\text { (DISCLOSURE1) }\end{array}$ & $\begin{array}{c}\text { The Scope of Internet } \\
\text { Reporting } \\
\text { (DISCLOSURE2) }\end{array}$ \\
\hline N & 101 & 101 & 101 \\
\hline Mean & 0.6048 & 12.2574 & 0.8812 \\
\hline Min & -5.6819 & 5 & 0 \\
\hline Max & 9.0122 & 20 & 4 \\
\hline Std. Dev. & 2.9446 & 3.4861 & 0.9725 \\
\hline Range & $\ddot{Y}$ & $0 \sim 40$ & $0 \sim 4$ \\
\hline
\end{tabular}

Table 9: Descriptive Statistics of the Variables of the Regression Model

Pearson Correlation Coefficient: Table 10 presents the Pearson coefficients of correlation. The coefficients between independent variables were below .5, indicating non-existence of high multicollinearity.

\begin{tabular}{|l|c|c|c|}
\hline Variables & CAR & DISCLOSURE1 & DISCLOSURE2 \\
\hline CAR & 1 & & \\
\hline DISCLOSURE1 & 0.300 & 1 & \\
\hline DISCLOSURE2 & 0.273 & 0.263 & 1 \\
\hline
\end{tabular}

Table 10: Pearson Correlation Matrix

Results of Multiple-Regression Analysis: Table 11 presents the results of applying multiple-regression analysis to determine the relationships between the dependent variable (abnormal return of stocks) and independent variables (the degree of the information disclosure (Disclosure1) and the scope of reporting (Disclosure2), on the internet). 
CAR $R_{i}=\alpha_{0}+\alpha_{1}$ DISCLOSURE $1_{i}+\alpha_{2}$ DISCLOSURE $2_{i}+\varepsilon_{i}$

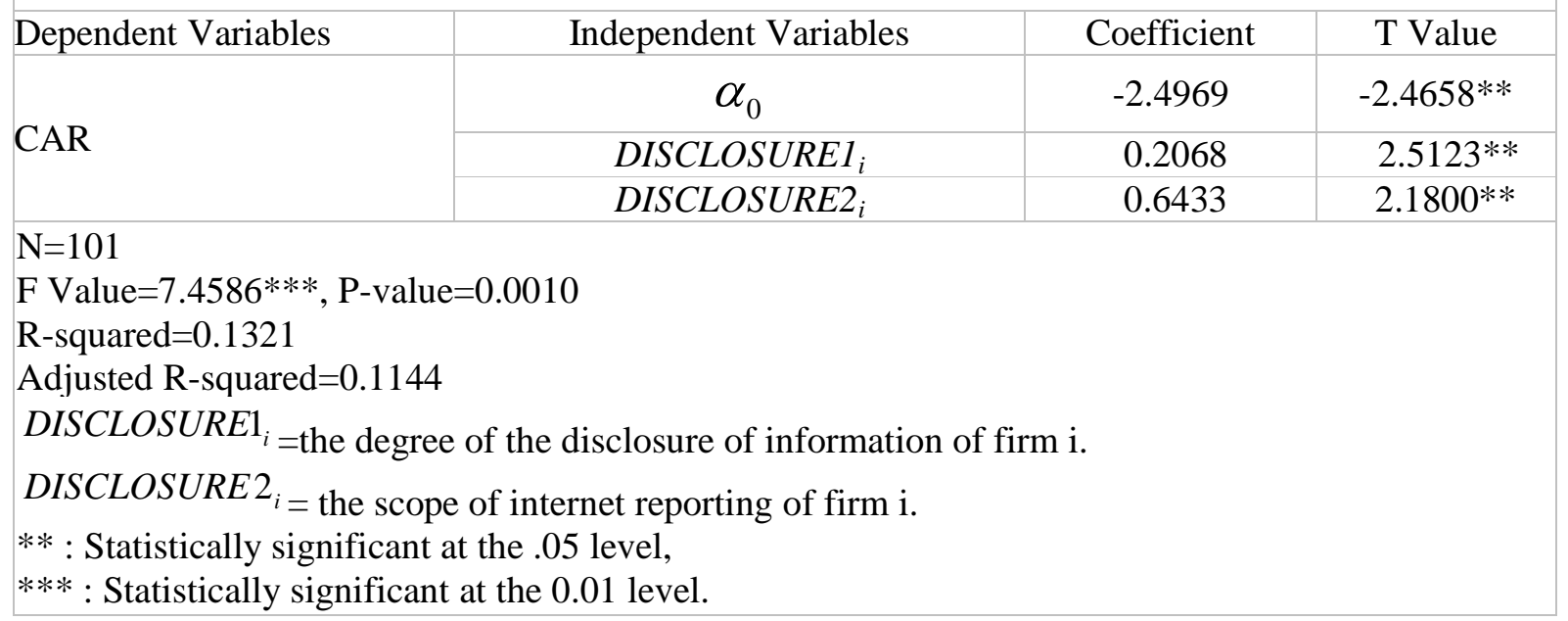

Table 11: Results of Multiple Regression

The coefficients revealed significant correlations between the dependent variable and the two independent variables, with $\mathrm{T}$ values significant at .05 confidence level. Thus, Hypothesis 4 (the degree of the disclosure of information has a significant impact on the abnormal return) and Hypothesis 5 (the scope of internet reporting has a significant impact on the abnormal return) can be accepted.

Robustness Checks: To control for industry and size effects, we re-ran the same regression model with two new control variables included in the model: size and industry.

\begin{tabular}{|c|c|c|c|}
\hline \multicolumn{4}{|c|}{$\operatorname{CAR}_{i}=\alpha_{0}+\alpha_{1}$ DISCLOSURE1 $_{i}+\alpha_{2}$ DISCLOSURE2 ${ }_{i}+\varepsilon_{i}$} \\
\hline $\begin{array}{l}\text { Dependent } \\
\text { Variables } \\
\end{array}$ & Independent Variables & Coefficient & T Value \\
\hline \multirow{5}{*}{ CAR } & Intercept & 1.5243 & 0.43 \\
\hline & DISCLOSURE $1_{I}$ & 0.2311 & $2.71 * * *$ \\
\hline & DISCLOSURE2 ${ }_{I}$ & 0.6350 & $2.02 * *$ \\
\hline & SIZE & -0.2774 & 0.04 \\
\hline & INDUSTRY & 0.0221 & -1.18 \\
\hline \multicolumn{4}{|c|}{$\begin{array}{l}\mathrm{N}=101 \\
\mathrm{~F} \text { Value }=4.12^{* * *}, \quad \mathrm{P} \text {-value }=0.004 \\
\mathrm{R} \text {-squared }=0.1478 \\
\text { Adjusted R-squared }=0.1119 \\
\end{array}$} \\
\hline \multicolumn{4}{|c|}{$\begin{array}{l}\text { DISCLOSURE } 1_{i}=\text { the degree of the disclosure of financial information of firm } \mathrm{i} . \\
\text { DISCLOSURE } 2_{i}=\text { the scope of internet reporting of firm i. } \\
\text { SIZE }=\text { the natural logarithm of the market value of equity at }-2 \text { trading day of event day. } \\
\text { INDUSTRY = dummy variable, equal to one if the firm is belong to electronic industry, and } 0 \text {, otherwise. } \\
\text { **: Statistically significant at the } 5 \% \text { level, } \\
\text { ***: Statistically significant at the } 1 \% \text { level. }\end{array}$} \\
\hline
\end{tabular}

Table 12: Robustness Test 
We use the natural logarithm of the market value of equity at -2 trading day of the event day to proxy for size and a dummy variable taking on the value of one if the firm belongs to the electronic industry to control for industry effect. Our initial results are robust in this new specification. As reported in Table 12, both the degree of information and the scope of information continue to be significant in this specification after controlling for size and industry effects. In fact, both size and industry variables are not significant in explaining the firm's cumulative abnormal returns.

To evaluate whether the weighted index for information disclosure has an impact on the regression results, we re-ran the models with disclosure scores tallied from an unweighted index. Our results are robust against the scaling systems adopted.

\section{CONCLUSIONS}

This study focuses on whether the disclosure of information on the internet, in terms of timeliness and relevance, has an immediate impact on stocks prices, and whether the degree of information disclosed on the internet and the scope of IFR have a significant impact on stocks prices. A number of conclusions can be drawn from our research findings.

First, the number of companies disclosing financial information on the internet is on the rise, but most of these firms tend to disclose summary (macro) financial data rather than a complete set of financial statements as required by the TSE for the quarterly and annual filing. Financial and electronic industries, a very significant part of Taiwan's economy, have strong financial systems and tend to disclose more information, both financial and non-financial, on the internet than other industries.

Secondly, the stock market's response to the firms providing timely information through IFR is faster than the corresponding response to firms without IFR. Moreover, the stock market's response to the firms providing more information on their websites is faster than the ones providing less information on their websites. Our findings suggest that when relevant information is provided on a timely basis regarding a firm's performance, investors will respond and reevaluate the firm's worth and readjust their portfolio, as a consequence.

Third, an important finding from this study was the confirmation that IFR firms experience abnormal returns as their financial information is disclosed via internet whereas their non-IFR counterparts do not experience any abnormal returns. One interesting finding worth pointing out from this study is that the market in Taiwan does not seem to respond to the website disclosure as soon as it is released; instead it takes additional two days before the market responds to the available new information. This is contrary to the prediction of the efficient market theory that if markets are efficient, then, 
in equilibrium, stock prices only respond when useful information is entering the market. One explanation for this contradictory phenomenon is that the Taiwanese market is not accustomed to analyze firms through firms' website disclosure. As a result, it takes additional time for the market to understand the reporting medium, and adjust stock prices of IFR firms accordingly.

Finally, the abnormal returns of a firm's stock increased as the degree and scope of disclosure increased. Our finding suggests that the greater the information transparency provided by a firm through disclosure, the higher the impact is on the stock prices of a firm.

While our results provide some interesting insights from the users' perspective into the relationship between a firm's stock prices and its internet financial reporting, our results should be interpreted in the light of the limitation due to the unique nature of the companies included in this study. The high representation of the electronic industry and strong financial institutions in our sample is the nature of the Taiwanese economy. Our results may not be representative of the economies in other parts of the world without similar industrial structure.

\section{REFERENCES}

ABDELSALAM, O.; BRYANT, S.; STREET, D. (2007): "An Examination of the Comprehensiveness of Corporate Internet Reporting Provided by London-Listed Companies", Journal of International Accounting Research 6(2): 1-33. http://dx.doi.org/1 $\underline{0.2308 / \mathrm{jiar} .2007 .6 .2 .1}$

AKAIKE, H. (1969): "Fitting Autoregressions for Prediction", Annuals of the Institute of Statistical Mathematics 21:243-247. http://dx.doi.org/10.1007/BF02532251

ALLAM, A.; A. LYMER, A. (2003): "Developments in Internet Financial Reporting: Review and Analysis across Five Developed Countries", The International Journal of Digital Accounting Research 3(6): 165-199. http://dx.doi.org/10.4192/1577-8517-v3_6

ASHBAUGH, H.; JOHNSTONE, K.; WARFIELD, T. (1999): “Corporate Reporting on the Internet", Accounting Horizons 13(3): 241-257. http://dx.doi.org/10.2308/acch.1999.1 3.3.241

BALL, R.; BROWN, P. (1968): "An Empirical Evaluation of Accounting Income Numbers", Journal of Accounting Research, Autumn: 159-178. http://dx.doi.org/10.2307/ 2490232

BEAVER, W. H. (1968): "The Information Content of Annual Earnings Announcements", Journal of Accounting Research 6(3): 67-92. http://dx.doi.org/10.2307/ 
$\underline{2490070}$

BONSÓN, E.; T. ESCOBAR, T. (2002): "A Survey on Voluntary Disclosure on the Internet: Empirical Evidence from 300 European Union Companies", The International Journal of Digital Accounting Research 2(1): 27-51. http://dx.doi.org/10.4192/15778517-v2_2

BOTOSAN, C. (1997): "Disclosure level and the Cost of Equity Capital", The Accounting Review 72: 323-349.

CHOW, G.C. (1960): "Tests of Equality between Sets of Coefficient in Two Linear Regressions", Econometrica, 28: 591-605. http://dx.doi.org/10.2307/1910133

CHU, G. W. (2001): "A Study of the Determining Factors of Internet Reporting by Business Enterprises", Master Thesis. The Graduate School of Accounting, National Taiwan University.

CRAVEN, B. M.; MARSTON, C.L. (1999): "Financial Reporting on the Internet by Leading UK Companies", The European Accounting Review 8(2): 321-333. http://dx.doi.org/10.1080/096381899336069

DEBRECENCY, R.; GRAY, G.L.; RAHMAN, A. (2002): “The Determinants of Internet Financial Reporting", Journal of Accounting and Public Policy 21: 371-394. http://dx.doi.org/10.1016/S0278-4254(02)00067-4

EASLEY, E.; HVIDKJAER, S.; O'HARA, M. (2002): "Is Information Risk a Determinant of Asset Returns?", Journal of Finance 57: 2185-2221. http://dx.doi.org/10. $\underline{1111 / 1540-6261.00493}$

EASLEY, E.; O'HARA, M. (2004): "Information and the Cost of Capital”, Journal of Finance 59: 1553-1584. http://dx.doi.org/10.1111/j.1540-6261.2004.00672.x

ETTREDGE, M.; RICHARDSON, V. J.; SCHOLZ, S. (2001): "The Presentation of Financial Information at Corporate Web Sites", International Journal of Accounting Information Systems, 2: 149-168. http://dx.doi.org/10.1016/S1467-0895(00)00017-8

ETTREDGE, M.; RICHARDSON, V. J.; SCHOLZ, S. (2002)a: "Dissemination of Information for Investors at Corporate Web sites", Journal of Accounting and Public Policy 21: 357-369. http://dx.doi.org/10.1016/S0278-4254(02)00066-2

ETTREDGE, M.; RICHARDSON, V. J.; SCHOLZ, S. (2002)b: “Timely Financial Reporting at Corporate Web Sites?", Communications of the ACM 45: 67-71. http://dx.doi.org/10.1145/508448.508450 
EZAT, A.; EL-MASRY, A. (2008): "The Impact of Corporate Governance on the Timeliness of Corporate Internet Reporting by Egyptian Listed Companies", Managerial Finance 31 (12): 848-867. http://dx.doi.org/10.1108/03074350810915815

FAMA, E. F., FISHER, L.; JENSEN, M. C.; ROLL, R. (1969): "The Adjustment of Stock Prices to New Information", International Economic Review 10 (1): 1-21. http://dx.doi.org/10.2307/2525569

FAMA, E. F. (1970): "Efficient Capital Markets: A Review of Theory and Empirical Work", Journal of Finance 25 (2): 383-417. http://dx.doi.org/10.2307/2325486

FAMA, E. F. (1976): Foundation of Finance, Basic Books, New York.

FINANCIAL ACCOUNTING STANDARDS BOARD (1980): Statement of Financial Accounting Concepts No. 2: Qualitative Characteristics of Accounting Information, Stamford, CT: FASB.

FINANCIAL ACCOUNTING STANDARDS BOARD (2000): Steering Committee Report Series, Business Reporting Research Project: Electronic Distribution of Business Reporting Information, January 31.

FRANKEL, R.; JOHNSON, M. ; SKINNER D.J. (1999): “An Empirical Examination of Conference Calls as a Voluntary Disclosure Medium", Journal of Accounting Research 37(1): 133-150. http://dx.doi.org/10.2307/2491400

HAYS, P. A.; UPTON, D. E., (1986): "A Shifting Regimes Approach to the Stationarity of Market Model Parameters of Individual Securities", Journal of Financial and Quantitative Analysis, 21: 307-321. http://dx.doi.org/10.2307/2331044

HIRST, D. E.; HOPKINS, P. E. (1998): "Comprehensive Income Reporting and Analysts' Valuation Judgments", Journal of Accounting Research 36: 47-75. http://dx.doi.org/10.2307/2491306

LARRÁN M.; GINER, B. (2002): "The Use of the Internet for Corporate Reporting by Spanish Companies", The International Journal of Digital Accounting Research 2(1): 5382. http://dx.doi.org/10.4192/1577-8517-v2_3

LASWAD, F; FISHER, R.; OYELERE, P. (2005): "Determinants of Voluntary Internet Financial Reporting by Local Government Authorities", Journal of Accounting and Pubic Policy 24(2): 101-121. http://dx.doi.org/10.1016/j.jaccpubpol.2004.12.006

LEFTWICH, R. W.; WATTS, R. L.; ZIMMERMAN, J. L. (1981): "Voluntary Corporate Disclosure: The Case of Interim Reporting", Journal of Accounting Research, 19 (Supplement): 50-77. http://dx.doi.org/10.2307/2490984 
LODHIA, S. K; ALLAM, A. ; LYMER, A. (2004): "Corporate Reporting on the Internet in Australia: An Exploratory Study", Australian Accounting Review (Nov): 64-71.

LYBAERT, N. (2002): "On-Line Financial Reporting: An Analysis of the Dutch Listed Firms", The International Journal of Digital Accounting Research 2(4): 195-234. http://d x.doi.org/10.4192/1577-8517-v2_7

MIKKELSON, W. H..; PARTCH, M. M. (1986): "Valuation Effects of Security Offerings and the Issuance Process", Journal of Financial Economics 15(1): 31-60. http://dx.doi.org/10.1016/0304-405X(86)90049-8

PIRCHEGGER, B.; WAGENHOFER, A. (1999): "Financial Information on the Internet: A Survey of the Homepages of Austrian Companies", The European Accounting Review 8(2): 383-395. http://dx.doi.org/10.1080/096381899336113

RICE, S. J. (1978): “The Information Content of Fully Diluted Earnings Per Share”, The Accounting Review 53(2): 429-438.

SENGUPTA, P. (1998): "Corporate Disclosure Quality and the Cost of Debt", The Accounting Review 73: 459-474.

SPENCE, M. (1973): “Job Market Signaling”, Quarterly Journal of Economics 87: 355374. http://dx.doi.org/10.2307/1882010

SHIVAKUMAR, L. (2000): "Do Firms Mislead Investors by Overstating Earnings before Seasoned Equity Offerings", Journal of Accounting and Economics 29(1): 339-371. http://dx.doi.org/10.1016/S0165-4101(00)00026-4

VERITY, J. W. (1994): "Ready or Not, the Electronic Mall is Coming", Business Week 3365: 84-85.

WELKER, M. (1995): "Disclosure Policy, Information Asymmetry, and Liquidity in Equity Markets", Contemporary Accounting Research, 11: 801-827. http://dx.doi.org/10. 1111/j.1911-3846.1995.tb00467.x

XIAO, J. Z., YANG, H.; CHOW, C.W. (2004): "The Determinants and Characteristics of Voluntary Internet-based Disclosures by Chinese Companies", Journal of Accounting and Public Policy 23(3): 191-225. http://dx.doi.org/10.1016/j.jaccpubpol.2004.04.002

YAN, H. H.; TSENG, H. C. (2001): "A Study of Internet Financial Reporting by Business Enterprises in Taiwan", Journal of Contemporary Accounting 2(2): 147-168.

YEO, G.H.; D.A. ZIEBART. (1995): “An Empirical Test of the Signaling Effects of Management's Earnings Forecasts: a Decomposition of the Earnings Surprise and Forecast Surprise Effects", Journal of Accounting, Auditing and Finance 10(4): 787-802. 